\title{
PENGARUH ATRIBUT PUSAT PERBELANJAAN TERHADAP KEPUASAN KONSUMEN DI KAWASAN SENTRA PRIMER JAKARTA BARAT (STUDI KASUS: LIPPO MALL PURI DAN PURI INDAH MALL)
}

\author{
Perez Januar Soewito \\ Magister Teknik Perencanaan, Universitas Tarumanagara, Jakarta \\ Email: perezjanuar@gmail.com
}

\begin{abstract}
ABSTRAK
SPBB Jakarta Barat merupakan sebuah pusat bisnis baru di mana terdapat 2 buah pusat perbelanjaan skala regional yaitu Puri Indah Mall dan Lippo Mall Puri. Kualitas atribut masing - masing pusat perbelanjaan memberikan pengalaman dan kepuasan belanja bagi konsumen. Hal ini menjadi menarik untuk dilihat bagaimana tingkat kepuasan konsumen pada persaingan pusat perbelanjaan di kawasan SPBB Jakarta Barat ini. Metode yang digunakan dalam penelitian ini adalah metode kuantitatif dengan mengukur tingkat kepuasan konsumen pada 7 atribut pusat perbelanjaan Puri Indah Mall dan Lippo Mall Puri. Penelitian dilakukan dengan menyebarkan kuesioner yang berisikan pertanyaan dan pernyataan mengenai profil konsumen dan 7 atribut pusat perbelanjaan pada 150 konsumen pusat perbelanjaan di Puri Indah Mall dan Lippo Mall Puri. Hasil kuesioner kemudian dianalisis menggunakan analisis Likert Scale untuk mengetahui atribut pusat perbelanjaan yang memiliki peringkat teratas sampai terbawah. Hasil dari penelitian ini adalah dari 7 atribut pusat perbelanjaan pada Puri Indah Mall dan Lippo Mall Puri, 3 atribut dengan nilai tertinggi adalah Lingkungan Mall, Kenyamanan, dan Tenant Pengisi. Sedangkan atribut dengan nilai terendah adalah penghargaan / reward sehingga perlu ditingkatkan lagi. Dari hasil perbandingan tingkat kepuasan menunjukkan bahwa konsumen lebih puas pada atribut Lippo Mall Puri dibandingkan dengan atribut Puri Indah Mall. Dari hasil analisis tersebut dapat disimpulkan bahwa Puri Indah Mall perlu lebih lagi meningkatkan kualitas atributnya agar konsumen - konsumen loyalnya dapat dipertahankan karena Lippo Mall Puri hadir dengan inovasi yang mampu menarik banyak konsumen.
\end{abstract}

Kata kunci: atribut, pusat perbelanjaan, kepuasan, konsumen

\section{PENDAHULUAN}

Banyaknya pembangunan Mall di Jakarta menunjukan bahwa tingginya budaya konsumtif masyarakat Jakarta dan mall bertransformasi tidak hanya sekedar tempat berbelanja namun juga sebagai tempat hiburan. Seiring perkembangannya, semua pusat perbelanjaan memiliki kesamaan di banyak bidang, mulai dari tenant, produk, dan harga (Ahmed, Ghingold,\& Dahari, 2007). Keberhasilan dan kegagalan suatu pusat perbelanjaan dapat dilihat dari usaha pusat perbelanjaan tersebut dalam berinovasi. Indikasi keberhasilan dan kegagalan tersebut mengarah pada keberadaan atribut mall yang mempengaruhi respon konsumen (Lazarus, 1991 dalam Wong $\mathrm{dkk}, 2012$ ).Atribut mall yang menarik dapat memberikan kepuasan pengalaman berbelanja yang menyenangkan (Baker dkk, 2002) karena konsumen selalu mencari tempat yang menurut persepsi mereka menarik (Jones dan Reynolds, 2006). Kepuasan konsumen akan pusat perbelanjaan sangat ditentukan oleh image mall beserta atribut - atributnya (Anderson \& Sullivan, 1993).

Konsumen lebih memilih pusat perbelanjaan yang menyediakan pengalaman yang berbeda dibanding dengan yang lain. Sebagian besar dari desain fisikya di mana desain tersebut memberikan nilai tambah juga bagi pengisi tenant di sana. Pusat perbelanjaan sebagai produk yang didesain harus berfungsi sesuai dengan harapan perancangnya yang dapat sesuai dengan kondisi masyarakat yang ada, baik keuntungan ekonomi maupun juga keuntungan emosional yang dibentuk oleh konsumen (Williams, 2006). Demikian dengan pusat perbelanjaan untuk dapat merancang strategi pemasaran yang efektif, mereka perlu memahami dan memperhatikan seluruh atribut yang membantu mereka menciptakan pengalaman berbelanja yang baru 
SPBB Jakarta Barat merupakan sebuah pusat bisnis baru di mana terdapat 2 pusat perbelanjaan atau mall yang memiliki daya tarik tersendiri yaitu Mall Puri Indah yang telah berdiri terlebih dahulu sejak 1997 dan Lippo Mall Puri yang baru saja dibuka pada tahun 2014 dengan mengusung konsep mixed use development. Hadirnya Lippo Mall Puri tentunya memberikan tambahan pilihan mall di kawasan ini dan tentunya kompetitor bagi Mall Puri Indah khususnya.

Sebagai mall baru, Lippo Mall Puri memiliki strategi tersendiri untuk membedakannya dari mall - mall yang lain. Demikian dengan Puri Indah Mall sebagai pusat perbelanjaan yang telah ada lebih dahulu pada kawasan ini juga terus melakukan inovasi dan renovasi guna terus mempertahankan kepuasan konsumennya. Kepuasan konsumen kedua mall tersebut menjadi penting karena sebagai pusat perbelanjaan, ramai dikunjungi dan memiliki konsumen konsumen yang loyal akan berguna bagi mall tersebut untuk dapat tetap hidup. Fungsi pusat perbelanjaan pada kawasan SPBB Jakarta Barat pun dapat berfungsi dengan baik dan dapat bersaing dengan kelompok - kelompok pusat perbelanjaan di tempat lain.

Kedua mall tersebut terus melakukan inovasi - inovasi untuk meningkatkan kualitas atributnya guna memberikan pengalaman baru dan kepuasan berbelanja kepada konsumen. Hal ini membuat peneliti tertarik untuk meneliti tentang kepuasan konsumen pada kedua mall ini atas atribut tersebut. Dengan mengetahui tingkat kepuasan konsumen ini, dapat memberikan gambaran penilaian strategi mall tersebut atas atribut mereka dan respon balik bagi kedua mall tersebut.

\section{METODE PENELITIAN}

Jenis penelitian ini adalah penelitian kuantitatif. Variabel yang digunakan dalam penelitian ini yaitu: 7 atribut mall yang meliputi kenyamanan, kualitas pelayanan, tenant pengisi, lingkungan mall, penghargaan, fokus pemasaran, dan keamanan \& pengamanan. 
Tabel 1. Variabel Penelitian

\begin{tabular}{|c|c|c|}
\hline No & $\begin{array}{l}\text { Atribut Pusat } \\
\text { Perbelanjaan }\end{array}$ & Sub Atribut \\
\hline A & $\begin{array}{l}\text { Lingkungan } \\
\text { Mall }\end{array}$ & $\begin{array}{l}\text { 1. Mall memiliki desain arsitektural baik eksterior dan interior yang menarik } \\
\text { 2. Mall memiliki pencahayaan dari luar maupun dalam dengan baik } \\
\text { 3. Mall memiliki suhu temperature yang baik } \\
\text { 4. Lingkungan mall bersih dan rapi }\end{array}$ \\
\hline B & Tenant Pengisi & $\begin{array}{l}\text { 1. Mall memiliki keberagaman tenant yang banyak } \\
\text { 2. Tenant yang dihadirkan memiliki kredibilitas yang tinggi } \\
\text { 3. Produk yang ditawarkan memiliki kualitas yang tinggi } \\
\text { 4. Kualitas dari Department Store } \\
\text { 5. Kualitas dari area F\&B } \\
\text { 6. Kualitas dari Food Court } \\
\text { 7. Kualitas dari retail Fashion } \\
\text { 8. Kualitas dari retail elektronik } \\
\text { 9. Kualitas dari Supermarket } \\
\text { 10. Kualitas dari Bioskop / Cinema } \\
\text { 11. Kualitas dari retail kebutuhan rumah tangga } \\
\text { 12. Kualitas dari pusat kebugaran dan kesehatan } \\
\text { 13. Kualitas dari arena bermain anak } \\
\text { 14. Kualitas dari fasilitas perbankan } \\
\text { 15. Kualitas dari retail toko buku }\end{array}$ \\
\hline $\mathrm{C}$ & Kenyamanan & $\begin{array}{l}\text { 1. Mall mudah dicapai baik melalui kendaraan umum dan juga kendaraan pribadi } \\
\text { 2. Jam operasional mall cukup lama } \\
\text { 3. Mall menyediakan semua kebutuhan sehari - hari. } \\
\text { 4. Mall menyediakan fasilitas aksesibilitas dengan baik } \\
\text { 5. Mall menyediakan fasilitas toilet dan musholla dengan bersih dan baik } \\
\text { 6. Pentujuk arah di dalam bangunan membantu sirkulasi pengunjung dengan baik } \\
\text { 7. }\end{array}$ \\
\hline $\mathrm{D}$ & Penghargaan & $\begin{array}{l}\text { 1. } \text { Mall sering menawarkan potongan harga } \\
\text { 2. Mall sering memberikan voucher gratis } \\
\text { 3. } \quad \text { Mall memberikan keuntungan lebih bagi para pelanggan tetapnya. }\end{array}$ \\
\hline $\mathrm{E}$ & $\begin{array}{c}\text { Fokus } \\
\text { Pemasaran }\end{array}$ & $\begin{array}{l}\text { 1. Mall sering mengadakan acara - acara yang atraktif dan menarik } \\
\text { 2. Mall memiliki alat pemasaran konvensional yang informatif (buletin, poster, } \\
\text { billboard, banner, iklan, dll) } \\
\text { 3. Mall memiliki alat pemasaran online yang menarik (website, media sosial, dll) }\end{array}$ \\
\hline $\mathrm{F}$ & $\begin{array}{c}\text { Kualitas } \\
\text { Pelayanan }\end{array}$ & $\begin{array}{l}\text { 1. Pelayanan konsumen ramah, bertanggung jawab, dan mampu memberikan } \\
\text { informasi yang akurat } \\
\text { 2. Penjual ramah, bertanggung jawab, dan mampu memberikan informasi yang akurat }\end{array}$ \\
\hline $\mathrm{G}$ & $\begin{array}{l}\text { Keamanan \& } \\
\text { Pengamanan }\end{array}$ & $\begin{array}{l}\text { 1. Penjaga keamanan sigap dalam bekerja } \\
\text { 2. Pengamanan terhadap aksi terorisme } \\
\text { 3. } \\
\text { 4. } \\
\text { Keamananan terhadap bencana atau kecelakaan } \\
\text { Kerhadap tindakan criminal }\end{array}$ \\
\hline
\end{tabular}

(Sumber: Ahmad, A. (2012), Bridsonet al (2008), Bruckset al (2000), Caruana et al (2000), IMN (2003), Kaufman, C. F. (1996), Overstreet, J. \& Clodfelter, R. (1995), Singh, H., Prashar, S. (2013), Wakefield et al (1998), Wirtz, J \& Chew, P. (2002), Wong et al (2012), Wilhelm, W., Mottner, S. (2005), Williams (2006), Yiu, C., \& Yau, Y. (2006), Yilmaz, V. (2004), Zakaria et al (2014) )

Metode pengumpulan data adalah dengan menyebaran kuesioner kepada responden yang telah dipilih secara acak. Kuesioner berisikan pernyataan dan pertanyaan yang akan digunakan untuk mendapatkan data yang diperlukan. Jenis skala pengukuran yang digunakan adalah skala Likert dengan dengan skor antara 1-5. Jawaban dengan nilai yang semakin besar menunjukkan penilaian yang semakin positif terhadap pernyataan yang diberikan dan sebaliknya. 
Penyebaran kuesioner dilakukan pada tengah minggu yaitu pada tingkat kepadatan kunjungan rendah dan akhir minggu pada tingkat kepadatan kunjungan tinggi. Waktu pengambilan sample adalah pada waktu siang hari dan malam hari di Puri Indah Mall dan Lippo Mall Puri. Pembagian ini dilakukan agar didapat karakter responden yang lebih beragam sesuai dengan waktu kedatangannya.

Populasi penelitian ini yaitu konsumen mall Lippo Mall Puri dan Mall Puri Indah yang pernah mengunjungi kedua mall tersebut minimal 2 kali, karena dengan demikian pengunjung tersebut diharapkan dapat mengetahui kondisi atribut dari kedua pusat perbelanjaan tersebut. Jumlah populasi tersebut tidak dapat diketahui secara pasti, sehingga digunakan metode dari Tabachnick $\&$ Fidell (2012), dengan rumus: $\mathrm{N}>50+8 \mathrm{M}$ ( $\mathrm{N}=$ jumlah sampel, $\mathrm{M}=$ jumlah variable bebas). Dari hasil perhitungan, jumah sampelnya adalah: $N>50+8(7)=N>106$. Pada penelitian ini jumlah sampel yang digunakan adalah sebanyak 150 sampel, di mana jumlah ini lebih banyak dari hasil perhitungan rumus yang telah dilakukan, dengan tujuan sampel tersebut dapat lebih mewakili populasi.

Analisis kuantitatif pada penelitian ini menggunakan alat analisis statistik. Metode pertama yang digunakan yaitu Analisis One Sample t-Test. Uji ini digunakan untuk mengetahui perbedaan ratarata populasi yang digunakan sebagai pembanding dengan rata-rata sebuah sampel. Dari hasil ini apakah akan diketahui bahwa rata-rata populasi yang digunakan sebagai pembanding secara signifikan berbeda dengan rata-rata sebuah sampel. Analisis ini juga digunakan untuk menguji apakah suatu nilai tertentu yang digunakan sebagai pembanding berbeda secara nyata ataukah tidak dengan rata-rata sebuah sampel. Nilai tertentu disini pada umumnya adalah sebuah nilai parameter untuk mengukur suatu populasi. Dalam penelitian ini maka analisis ini bertujuan untuk menyimpulkan apakah terdapat cukup bukti bahwa konsumen puas terhadap atribut atribut pusat perbelanjaan yang ditanyakan dan juga untuk menguji perbandingan nilai rata - rata dari atribut kedua pusat perbelanjaan.

Analisis kedua adalah analisis Relative Rank Index. Analisis ini untuk melihat variabel variabel atribut apa saja yang paling dominan berpengaruh pada kepuasan konsumen. Analisis dilakukan dengan mengurutkan setiap sub atribut pusat perbelanjaan dari nilai paling tinggi sampai yang paling rendah. Nilai yang tinggi menandakan faktor tersebut yang dominan terhadap kepuasan konsumen.

\section{HASIL DAN PEMBAHASAN}

Profil konsumen dari kedua mall adalah mayoritas berusia muda yaitu 21 - 30 tahun (61.33\%), belum menikah (66\%), dan dengan tingkat pendapatan menengah. Frekuensi berkunjung ke Puri Indah Mall atau pun Lippo Mall Puri dalam sebulan hampir $60 \% 0-2$ kali dengan lama berkunjung 39,33\% 2 - 3 jam. Jenis retail yang menjadi favorit baik di Puri Indah Mall dan Lippo Mall Puri adalah retail FnB. Untuk mengetahui besar pengaruh dari atribut pusat perbelanjaan Puri Indah Mall dan Lippo Mall Puri terhadap kepuasan konsumennya, hasil kuesioner yang telah diolah menggunakan Likert Scale Analysis diolah kembali dengan metode RRI / Relative Rank Index, yaitu diurutkan dari nilai index tertinggi ke nilai index terendah. 
Tabel 2. Analisis RRI Atribut Pusat Perbelanjaan

Puri Indah Mall dan Lippo Mall Puri

\begin{tabular}{|c|c|c|c|c|c|}
\hline \multirow{2}{*}{ Rank } & \multirow{2}{*}{ Atribut } & \multicolumn{2}{|c|}{ Pusat Perbelanjaan } & \multirow{2}{*}{ Atribut } & \multirow{9}{*}{$\begin{array}{c}\text { (Sumb } \\
\text { er: } \\
\text { Hasil } \\
\text { Olaha } \\
\text { n } \\
\text { Kuesio } \\
\text { ner, } \\
2016)\end{array}$} \\
\hline & & Puri Indah Mall & Lippo Mall Puri & & \\
\hline 1 & Kenyamanan & 3,73 & 3,97 & Lingkungan Mall & \\
\hline 2 & Lingkungan Mall & 3,65 & 3,77 & Kenyamanan & \\
\hline 3 & Tenant Pengisi & 3,59 & 3,74 & Tenant Pengisi & \\
\hline 4 & Kualitas Pelayanan & 3,35 & 3,61 & Kualitas Pelayanan & \\
\hline 5 & Keamanan \& Pengamanan & 3,20 & 3,55 & Fokus Pemasaran & \\
\hline 6 & Fokus Pemasaran & 3,02 & 3,40 & Keamanan \& Pengamanan & \\
\hline 7 & Penghargaan & 2,80 & 3,36 & Penghargaan & \\
\hline
\end{tabular}

3 atribut yang memberikan pengaruh paling tinggi pada kepuasan konsumen Puri Indah Mall dan Lippo Mall Puri adalah Lingkungan Mall, Kenyamanan, dan Tenant Pengisi. Pusat perbelanjaan di Jakarta khususnya sudah banyak memiliki kesamaan dalam hal tenant sehingga konsumen lebih mencari pusat perbelanjaan yang memiliki lingkungan yang menarik, yaitu pusat perbelanjaan yang mampu memberikan suasana yang baru bagi konsumen yang ingin berbelanja ataupun hanya sekedar berjalan - jalan dan nongkrong bersama rekan yang diajak. Suasana yang diciptakan melalui desain arsitektural dan kenyamanan dari fasilitas - fasilitas yang ditawarkan dapat menyebabkan konsumen menghabiskan waktu lebih lama pada pusat perbelanjaan tersebut, dan efeknya konsumen berpeluang dapat lebih banyak melakukan transaksi belanja di dalam mall tersebut. Atribut yang paling rendah atau paling lemah adalah atribut fokus pemasaran dan penghargaan. 2 atribut yang paling rendah ini yang perlu menjadi perhatian untuk ditingkatkan lagi kualitasnya sehingga kepuasan konsumen akan hal ini dapat meningkat.

Selanjutnya dilakukan analisis One Sample t-Test untuk menyimpulkan bahwa cukup bukti konsumen puas dengan variabel atribut yang diuji pada penelitian ini. Analisis dilakukan dengan melakukan tes melalui program SPSS menggunakan data jawaban kuesioner yang telah diolah. Hasil dari uji t-Test ini terhadap Puri Indah Mall adalah terdapat 5 sub atribut dari 38 sub atribut yang dinilai kurang memuaskan konsumen karena memiliki hasil t-hitung yang leih kecil dari ttabel dan nilai p-value yang leih besar dari $\alpha=0.05$. Sub atribut tersebut yaitu sub atribut D1, D2, dan D3 yang merupakan bagian dari atribut Penghargaan dan juga sub atribut E2 dan E3 yang merupakan bagian dari atribut Fokus Pemasaran. Sedangkan dari hasil uji terhadap Lippo Mall Puri adalah terdapat 2 sub atribut dari 38 sub atribut yang dinilai kurang memuaskan konsumen, yaitu sub atribut B14 dan sub atribut D2.

Dari hasil yang ada lalu dilakukan perbandingan hasil antara kedua mall tersebut untuk melihat mall mana yang dinilai lebih memuaskan konsumennya dan dapat dilihat pada tabel 3 berikut. 
Tabel 3. Analisis Perbandingan Atribut Pusat Perbelanjaan Berdasarkan Kepuasan Konsumen

\begin{tabular}{|c|c|c|c|c|c|c|}
\hline Atribut & Sub Atribut & $\begin{array}{c}\text { Mean } \\
\text { (LMP) }\end{array}$ & $\begin{array}{l}\text { Mean } \\
\text { (PIM) }\end{array}$ & t-value & $\begin{array}{c}\text { p- } \\
\text { value }\end{array}$ & Hipotesis \\
\hline \multirow[t]{4}{*}{$\begin{array}{l}\text { A. } \\
\text { Lingkungan } \\
\text { Mall }\end{array}$} & $\begin{array}{l}\text { Mall memiliki desain arsitektural } \\
\text { baik eksterior dan interior yang } \\
\text { menarik }\end{array}$ & 4.05 & 3.43 & 7.688 & 0.000 & Reject H0 \\
\hline & $\begin{array}{l}\text { 2. Mall memiliki pencahayaan dari } \\
\text { luar maupun dalam dengan baik }\end{array}$ & 3.94 & 3.61 & 3.974 & 0.000 & Reject H0 \\
\hline & $\begin{array}{l}\text { 3. Mall memiliki suhu temperature } \\
\text { yang baik }\end{array}$ & 3.87 & 3.79 & 0.980 & 0.164 & Do not reject $\mathrm{H} 0$ \\
\hline & 4. Lingkungan mall bersih dan rapi & 4.01 & 3.78 & 3.040 & 0.001 & Reject $\mathrm{H} 0$ \\
\hline \multirow[t]{15}{*}{$\begin{array}{l}\text { B. Tenant } \\
\text { Pengisi }\end{array}$} & $\begin{array}{l}\text { Mall memiliki keberagaman } \\
\text { tenant yang banyak }\end{array}$ & 4.14 & 3.44 & 7.684 & 0.000 & Reject H0 \\
\hline & $\begin{array}{l}\text { 2. Tenant yang dihadirkan memiliki } \\
\text { kredibilitas yang tinggi }\end{array}$ & 4.00 & 3.57 & 6.175 & 0.000 & Reject H0 \\
\hline & $\begin{array}{l}\text { 3. Produk yang ditawarkan memiliki } \\
\text { kualitas yang tinggi }\end{array}$ & 3.97 & 3.57 & 6.206 & 0.000 & Reject H0 \\
\hline & 4. Kualitas dari Department Store & 3.83 & 3.33 & 6.323 & 0.000 & Reject H0 \\
\hline & 5. Kualitas dari area F\&B & 3.89 & 3.95 & -0.736 & 0.231 & Do not reject $\mathrm{H} 0$ \\
\hline & 6. Kualitas dari Food Court & 3.67 & 3.62 & 0.601 & 0.274 & Do not reject $\mathrm{H} 0$ \\
\hline & 7. Kualitas dari retail Fashion & 4.03 & 3.29 & 8.177 & 0.000 & Reject HO \\
\hline & 8. Kualitas dari retail elektronik & 3.63 & 3.40 & 3.660 & 0.000 & Reject H0 \\
\hline & 9. Kualitas dari Supermarket & 3.76 & 3.63 & 1.696 & 0.046 & Reject H0 \\
\hline & 10. Kualitas dari Bioskop / Cinema & 4.14 & 4.05 & 1.684 & 0.047 & Reject H0 \\
\hline & $\begin{array}{l}\text { 11. Kualitas dari retail kebutuhan } \\
\text { rumah tangga }\end{array}$ & 3.58 & 3.59 & -0.085 & 0.466 & Do not reject $\mathrm{H} 0$ \\
\hline & $\begin{array}{l}\text { 12. Kualitas dari pusat kebugaran dan } \\
\text { kesehatan }\end{array}$ & 3.75 & 3.63 & 1.785 & 0.038 & Reject H0 \\
\hline & 13. Kualitas dari arena bermain anak & 3.73 & 3.36 & 3.927 & 0.000 & Reject H0 \\
\hline & 14. Kualitas dari $\mathrm{f}$ & 2.80 & 3.59 & -7.184 & 0.000 & Do not reject $\mathrm{H} 0$ \\
\hline & 15. Kualitas dari retail toko buku & 3.19 & 3.77 & -5.662 & 0.000 & Do not reject $\mathrm{H} 0$ \\
\hline \multirow[t]{7}{*}{$\begin{array}{l}\text { C. } \\
\text { Kenyamanan }\end{array}$} & $\begin{array}{l}\text { 1. Mall mudah dicapai baik melalui } \\
\text { kendaraan umum dan juga } \\
\text { kendaraan pribadi }\end{array}$ & 3.85 & 3.80 & 0.956 & 0.170 & Do not reject $\mathrm{HO}$ \\
\hline & 2. Jam operasional mall cukup lama & 3.81 & 3.85 & -0.610 & 0.271 & Do not reject $\mathrm{HO}$ \\
\hline & $\begin{array}{l}\text { 3. Mall menyediakan semua } \\
\text { kebutuhan sehari - hari. }\end{array}$ & 3.66 & 3.79 & -1.840 & 0.034 & Do not reject $\mathrm{H} 0$ \\
\hline & $\begin{array}{l}\text { 4. Mall menyediakan fasilitas } \\
\text { aksesibilitas dengan baik }\end{array}$ & 3.95 & 3.89 & 0.842 & 0.200 & Do not reject $\mathrm{H} 0$ \\
\hline & $\begin{array}{l}\text { 5. Mall menyediakan fasilitas toilet } \\
\text { dan musholla dengan bersih dan } \\
\text { baik }\end{array}$ & 4.10 & 3.72 & 4.745 & 0.000 & Reject H0 \\
\hline & $\begin{array}{l}\text { 6. Pentujuk arah di dalam bangunan } \\
\text { membantu sirkulasi pengunjung } \\
\text { dengan baik }\end{array}$ & 3.73 & 3.65 & 0.913 & 0.181 & Do not reject $\mathrm{H} 0$ \\
\hline & $\begin{array}{l}\text { 7. Kemudahan memarkirkan } \\
\text { kendaraan }\end{array}$ & 3.26 & 3.41 & -1.407 & 0.081 & Do not reject $\mathrm{H} 0$ \\
\hline \multirow[t]{2}{*}{$\begin{array}{l}\text { D. } \\
\text { Penghargaan }\end{array}$} & $\begin{array}{l}\text { 1. Mall sering menawarkan potongan } \\
\text { harga }\end{array}$ & 3.47 & 3.07 & 4.757 & 0.000 & Reject H0 \\
\hline & $\begin{array}{l}\text { 2. Mall sering memberikan voucher } \\
\text { gratis } \\
\text { 3. Mall memberikan keuntungan } \\
\text { lebih bagi para pelanggan } \\
\text { tetapnya. }\end{array}$ & 3.07 & 2.59 & 6.531 & 0.000 & Reject H0 \\
\hline E. Fokus & Mall sering mengadakan acara - & 3.56 & 3.17 & 5.122 & 0.000 & Reject H0 \\
\hline
\end{tabular}




\begin{tabular}{|c|c|c|c|c|c|c|}
\hline Pemasaran & $\begin{array}{l}\text { acara yang atraktif dan menarik } \\
\text { 2. Mall memiliki alat pemasaran } \\
\text { konvensional yang informatif } \\
\text { (buletin, Poster, billboard, banner, } \\
\text { iklan, dll) } \\
\text { 3. Mall memiliki alat pemasaran } \\
\text { online yang menarik (website, } \\
\text { media sosial, dll) }\end{array}$ & 3.39 & 2.93 & 5.816 & 0.000 & Reject H0 \\
\hline $\begin{array}{l}\text { F. Kualitas } \\
\text { Pelayanan }\end{array}$ & $\begin{array}{l}\text { 1. Pelayanan konsumen ramah, } \\
\text { bertanggung jawab, dan mampu } \\
\text { memberikan informasi yang } \\
\text { akurat } \\
\text { 2. Penjual ramah, bertanggung } \\
\text { jawab, dan mampu memberikan } \\
\text { informasi yang akurat }\end{array}$ & 3.60 & 3.37 & 4.771 & 0.000 & Reject $\mathrm{H} 0$ \\
\hline $\begin{array}{l}\text { G. } \\
\text { Keamanan \& } \\
\text { Pengamanan }\end{array}$ & $\begin{array}{ll}\text { 1. } & \text { Penjaga keamanan sigap dalam } \\
\text { bekerja } \\
\text { 2. Pengamanan terhadap aksi } \\
\text { terorisme } \\
\text { 3. Keamanan terhadap bencana atau } \\
\text { kecelakaan } \\
\text { 4. Keamanan terhadap tindakan } \\
\text { kriminal } \\
\quad \text { Rata - rata } \\
\end{array}$ & $\begin{array}{l}3.45 \\
3.31\end{array}$ & $\begin{array}{l}3.36 \\
3.13 \\
3.14\end{array}$ & $\begin{array}{r}1.906 \\
4.992 \\
2.738\end{array}$ & $\begin{array}{l}0.029 \\
0.000 \\
0.003 \\
0.001\end{array}$ & $\begin{array}{l}\text { Reject } \mathrm{H} 0 \\
\text { Reject H0 } \\
\text { Reject H0 } \\
\text { Reject H0 }\end{array}$ \\
\hline
\end{tabular}

(Sumber: Hasil Olahan Penulis Melalui SPSS, 2016)

Hasilnya adalah dari 38 sub atribut pusat perbelanjaan yang diuji, Lippo Mall Puri terbukti memiliki 26 sub atribut dengan tingkat kepuasan konsumen lebih tinggi dibandingkan dengan Puri Indah Mall karena 26 sub atribut tersebut yang telah diuji t - Test, menghasilkan nilai thitung yang lebih besar dari t-tabel dan nilai p-value lebih kecil dari $\alpha=0.05$. Sedangkan Puri Indah Mall terbukti memiliki 12 sub atribut dengan tingkat kepuasan konsumen lebih tinggi dibandingkan dengan Lippo Mall Puri. Secara keseluruhan dilihat dari rata - rata nilai kepuasan antara 2 mall tersebut dapat dikatakan bahwa konsumen lebih puas pada atribut Lippo Mall Puri dibandingkan dengan atribut Puri Indah Mall. Sehingga dapat disimpulkan bahwa cukup bukti ada pengaruh antara atribut pusat perbelanjaan terhadap kepuasan konsumen pada pusat perbelanjaan di kawasan SPBB Jakarta Barat, karena terdapat nilai tingkat kepuasan konsumen yang berbeda di antara 2 pusat perbelanjaan tersebut.

\section{KESIMPULAN DAN SARAN}

Pada kawasanSPBB Jakarta Barat terdapat pengelompokanpusat perbelanjaan baru yaitu Puri Indah Mall dan Lippo Mall Puri. Konsumen - konsumen dari Puri Indah Mall mendapat alternatif tempat berbelanja yang barudi dalam kawasan Puri Indah yaitu di Lippo Mall Puri yang menawarkan konsep dan produk - produk yang lebih baru. Di lain pihak, Puri Indah Mall juga melakukan pengembangan baru dan renovasi untuk dapat terus bersaing.

Kedua pusat perbelanjaan menawarkan atribut pusat perbelanjaan yang berbeda kepada konsumen dan kepuasan konsumen atas masing - masing atribut yang memiliki karakter tersendiri menjadi penting untuk dilihat untuk mengetahui persaingan pusat perbelanjaan. Atribut yang paling dominan adalah Lingkungan Mall, Kenyamanan, dan Tenant Pengisi. Hal ini menandakan bahwa konsumen dengan usia muda lebih memperhatikan suasana dan pengalaman yang mereka dapat dari pusat perbelanjaan. Selain itu dari analisis terlihat bahwa atribut reward 
dan fokus pemasaran merupakan atribut yang sama - sama mendapat nilai rendah pada Puri Indah Mall dan Lippo Mall Puri. Hal ini menandakan bahwa kedua mall perlu meningkatkan lagi kualitas atribut - atribut tersebut.

Atribut yang paling memuaskan bagi konsumen Puri Indah Mall adalah atribut kenyamanan dengan nilai rata - rata 3,73, sedangkan atribut yang paling memuaskan bagi konsumen Lippo Mall Puri adalah atribut lingkungan mall dengan nilai rata - rata 3,97. Sub atribut yang paling memuaskan bagi konsumen Puri Indah Mall adalah kualitas dari bioskop dengan nilai 4,05 dan $\mathrm{F} \& \mathrm{~B}$ area dengan nilai 3,95, sedangkan sub atribut yang paling memuaskan bagi konsumen Lippo Mall Puri adalah keberagaman tenant yang banyak dengan nilai 4,14 dan kualitas dari bioskop dengan nilai 4,14.

Dari antara 38 sub atribut yang dibandingkan antara kedua mall tersebut, 26 sub atribut Lippo Mall Puri memiliki tingkat kepuasan konsumen lebih tinggi dibandingkan sub atribut Puri Indah Mall, sedangkan 12 sub atribut dari Puri Indah Mall memiliki tingkat kepuasan konsumen lebih tinggi dibandingkan dengan sub atribut Lippo Mall Puri. Secara keseluruhan dapat terlihat bahwa atribut pusat perbelanjaan dari Lippo Mall Puri lebih memuaskan konsumen dibandingkan dengan atribut pusat perbelanjaan dari Puri Indah Mall. Hal ini menandakan konsumen konsumen Puri Indah Mall juga tertarik kepada Lippo Mall Puri oleh karena pengaruh dari atribut Lippo Mall Puri terhadap kepuasan mereka.

Bagi pengelola dan pengembang dari Puri Indah Mall, perlu mempertahankan kualitas dari lingkungan mall dan kenyamanan karena 2 hal ini menjadi faktor yang dinilai paling memuaskan dari konsumen. Kualitas fisik bangunan baik eksterior dan interior perlu dipertahankan kualitasnya, demikian juga dengan fasilitas - fasilitas yang ada di dalam mall yang mempengaruhi kepuasan dan perilaku berbelanja konsumen, sehingga konsumen dapat tetap nyaman untuk datang.

Perlu juga dilakukan pembaharuan tenant khususnya bagi tenant - tenant fashion, agar dapat lebih lagi bersaing dengan mall - mall lain dan lebih memuaskan konsumen - konsumennya. Kualitas dari F\&B yang sudah ada juga patut dipertahankan kualitasnya karena telah menjadi salah satu kekuatan dari Puri Indah Mall sebagai daya tarik konsumen untuk datang.

Selain itu, perlu ditingkatkan lagi program - program marketing dan reward untuk lebih lagi dapat menarik perhatian konsumen dan meningkatkan kepuasan konsumen di tengah persaingan dengan pusat berbelanjaan lainnya. Kondisi lingkungan mall yang berada di tengah - tengah kawasan perumahan dan profil pengunjung yang mayoritas usia - usia muda baik yang sudah berkeluarga maupun yang belum, sangat tertarik akan promosi - promosi dalam berbelanja. Puri Indah Mall mungkin dapat lebih mencoba membuat event dan promosi yang unik. Di tengah kuatnya peran media sosial saat ini, pihak mall dapat lebih lagi memaksimalkan potensi dari sektor ini untuk dapat melakukan promosi - promosi yang atraktif dan interaktif, sehingga dapat lebih banyak lagi menarik konsumen.

Bagi pengelola dan pengembang dari Lippo Mall Puri,sebagai mall yang baru pada kawasan ini telah melakukan langkah yang baik dengan inovasi - inovasi program berbelanja yang dilakukan serta tenant - tenant yang dihadirkan juga memiliki merk yang ternama. Konsumen banyak yang tertarik untuk datang ke mall ini karena event - event dan promosi - promosi yang dilakukan. Hal ini perlu dipertahankan dan dijaga kualitasnya, agar tidak kehilangan konsumen - 
konsumennya di masa mendatang, karena di lain pihak, Puri Indah Mall juga melakukan pembenahan dan telah lebih dahulu memiliki konsumen - konsumen loyalnya. Lippo Mall Puri juga diharap dapat lebih lagi memperhatikan masalah - masalah kenyamanan pengunjung terutama pada fasilitas perbankan yang dirasa masih kurang memuaskan oleh konsumennya.

\section{Ucapan Terima Kasih}

Puji syukur kepada Tuhan Yang Maha Esa atas berkat dan anugerah-Nya sehingga penulis dapat menyelesaikan penelitian ini. Segala kendala dan masalah yang terjadi dapat dilewati oleh karena kemurahan-Nya saja. Penulisan ini tidak dapat selesai tanpa dukungan dan bantuan dari berbagai pihak baik secara langsung maupun tidak langsung. Pada kesempatan ini, penulis ingin mengucapkan terima kasih banyak kepada:

1. Ibu Ir. Joyce Heryanto, M.Sc selaku dosen pembimbing pertama

2. Bapak Ir. Hari Ganie, M.M selaku dosen pembimbing kedua

3. Bapak Dr. Ing. Jo Santoso selaku Ketua Program Studi S2 Magister Teknik Perencanaan Universitas Tarumanagara

4. Para dosen dan staf Program Studi S2 Magister Teknik Perencanaan Universitas Tarumanagara

5. Orang tua, adik, dan saudara - saudara atas dukungan dan doanya

6. Jane Cindy yang terus mendukung, mendoakan, dan memberikan semangat

7. Teman - teman angkatan 22 MTP Universitas Tarumanagara atas semangat dan masukan pendapat yang diberikan

8. Seluruh pihak yang tidak dapat disebutkan satu per satu

Penulis menyadari bahwa tulisan ini masih jauh dari sempurna karena adanya keterbatasan waktu, kemampuan, pengetahuan, dan pengalaman yang penulis miliki. Untuk itu, penulis dengan rendah hati mengharapkan kritik dan saran yang membangun. Akhir kata, penulis berharap semoga tulisan ini dapat berguna bagi para pembaca dan semua pihak yang membutuhkan.

\section{REFERENSI}

Ahmad, A. (2012). Attractiveness Factors Influencing Shoppers' Satisfaction, Loyalty, and Word of Mouth: An Empirical Investigation of Saudi Arabia Shopping Malls. International Journal of Business Administration

Ahmed, Z. U., Ghingold, M., \& Dahari, Z. (2007). Malaysian shopping mall behavior: an exploratory study. Asia Pacific Journal of Marketing and Logistics , 19 (4), 331-348.

Anderson, E. \& Sullivan, M. (1993). The Antecedents And Consequences Of Customer Satisfaction For Firms. Marketing Science, 12, 125-43.

Baker, Julie, Parasuraman, A., Grewal, Dhruv, Voss, Glenn B. (2002). The Influence Of Multiple Store Environment Cues On Perceived Merchandise Value And Patronage Intentions,. Journal of Marketing 66 (2), 120-141.

Bridson, K, Evans, J \& Hickman, M. (2008). Assessing The Relationship Between Loyalty Program Attributes, Store Satisfaction And Store Loyalty. Journal of Retailing and Consumer Services, vol. 15, pp. 364-474.

Brucks, M., Zeithaml, V. A. and Naylor, G. (2000). Price and brand name as indicators of quality dimensions for consumer durables. Journal of the Academy of Marketing Science, 28 (3), 359-374. 
Caruana, A, Money, AH \& Berthon, P. (2000). Service Quality And Satisfaction: The Moderating Role Of Value. European Journal of Marketing, vol. 34, nos. 11/12, pp.13381353.

IMN. (2003). Informative Marketing TM - Equal Parts Technology. Publishing \& Customer Respect.

Jones, M., Reynolds, K., Arnold, M. (2006). Hedonic and utilitarian shopping value: investigating differential effects on retail outcomes. Journal of Business Research 59, 974-981.

Kaufman, C. F. (1996). A new look at one-stop shopping: a TIMES model approach to matching store hours and shopper schedules. Journal of Consumer Marketing , 13 (1), 452.

Overstreet, J. \& Clodfelter, R. (1995). Safety and Security Concerns of Shopping Center Customers and the Effect of these Concerns on Shopping Behavior. Journal of Shopping Center Research. Vol. 2, pp. 91 - 109

Singh, H., Prashar, S. (2013). Factors Defining Shopping Experience: An Analytical Study of Dubai. Asian Journal of Business Research.

Tabachnick, B. G., \& Fidell, L. S. (2012). Using Multivariate Statistics (6th Edition ed.). Prentice Hall PTR.

Williams. (2006). Design for Experience: A New Rationale. Journal of Design Education and Technology. vol. 2, pp. 9-19.

Wakefield, Kirk L., Baker, Julie (1998). Excitement at the Mall: Determinants and Effects on Shopping Responses. Journal of Retailing, Vol 74 (4), pp 515-540.

Wong, C., Wong, K., Wong, M., \& Cheong, H. (2012). The Relationship between Shopping Mall Attributes, Customer Satisfaction and Positive Word Of Mouth: China Visitors in Hong Kong. HongKong Shue Yan University. Global Journal of Management and Business Research.

Wilhelm, W., Mottner, S. (2005). Teens and Shopping Mall Preferences: A Conjoint Analysis Approach to Understanding the Generational Shift Toward an Experience Economy. Journal of Shopping Center Research, Vol 12 (1), pp 23-52.

Williams. (2006). Design for Experience: A New Rationale. Journal of Design Education and Technology. vol. 2, pp. 9-19.

Wirtz, J \& Chew, P. (2002), The Effects Of Incentives ,Deal Proneness, Satisfaction And Tie Strengthen On Word-Of-Mouth Behavior. International Journal of Service Industry Management, vol. 13, no. 2, pp. 141-162.

Yiu, C., \& Yau, Y. (2006). An Ecological Frameworkfor The Strategic Positioning Of A Shopping Mall.Journal of Retail and Leisure Property ,5(4), 270-280.

Yilmaz, V. (2004). Consumer Behaviour In Shopping Centre Choice. Social Behaviour and Personality, vol 32 (8), $783-790$.

Zakaria, I., Rahman, B. A., Othman, A. K., Azlina, N., Yunus, M., Dzulkipli, M. R., $\quad$ et $\quad$ al. (2014). The Relationship Between Loyalty Program, Customer Satisfaction and Customer Loyalty in Retail Industry: A Case Study.Journal ofSocial and Behavioral Sciences , 129, 23-30. 